\title{
Plant resistance in different cell layers affects aphid probing and feeding behaviour during poor- and non-host interactions
}

Carmen Escudero-Martinez ${ }^{1,2 \S}$, Daniel J. Leybourne ${ }^{1,2 \S}$, Jorunn I.B. Bos ${ }^{1,2^{*}}$

${ }^{1}$ Cell and Molecular Sciences, The James Hutton Institute, Invergowrie, Dundee, DD2 5DA, UK

${ }^{2}$ Division of Plant Sciences, School of Life Sciences, University of Dundee, Dundee

$\S$ these authors contributed equally

${ }^{*}$ Corresponding Author:

Jorunn I.B. Bos, PhD

Division of Plant Sciences, School of Life Sciences, University of Dundee

Cell and Molecular Sciences, James Hutton Institute

Invergowrie, Dundee

DD2 5DA

United Kingdom

Phone: +44 (0)3449285428

Email: j.bos@dundee.ac.uk 


\section{Abstract}

Aphids are phloem-feeding insects that cause economic losses to crops globally. Whilst aphid interactions with susceptible plants and partially resistant genotypes have been well characterised with regards to aphid probing and feeding behaviour, the interactions with non-natural host species are not well understood. Using aphid choice assays with the broad host range pest Myzus persicae and the cereal pest Rhopalosiphum padi we show that about $10 \%$ of aphids settle on non-/poor-host species over a $24 \mathrm{~h}$ time period. We used the Electrical Penetration Graph technique to assess aphid probing and feeding behaviour during the non-/poor-host interactions. In the Arabidopsis non-host interaction with the cereal pest $R$. padi aphids were unable to reach and feed from the phloem, with resistance likely residing in the mesophyll cell layer. In the barley poor-host interaction with M. persicae, resistance is likely phloem-based as aphids were able to reach the phloem but ingestion was reduced compared with the host interaction. Overall our data suggests that plant resistance to aphids in non-host and poor-host interactions with these aphid species likely resides in different plant cell layers. Future work will take into account specific cell layers where resistances are based to dissect the underlying mechanisms and gain a better understanding of how we may improve crop resistance to aphids.

Keywords: aphid, EPG analyses, nonhost, plant resistance, probing, stylet pathway. 
1

2

3

\section{Introduction}

Aphids are important insect pests which cause significant yield losses to crops globally (Blackman R, 2000). There are approximately 5000 aphid species described and around 250 of these are important agricultural and horticultural pests which vary in their host range - the ability to successfully infest different plant species. This host range variation generally applies to secondary hosts during summer months, where aphid populations increase rapidly due to asexual reproduction (Moran, 1992). Whilst the majority of aphid species exhibit a limited host range, dedicated to few closely related plant species, some aphid species, like Myzus persicae Sulzer (green peach aphid), have an exceptionally broad host range which includes representatives from more than 40 plant families (Blackman R, 2000, Powell et al., 2006). The evolutionary drivers and molecular determinants of such exceptionally broad host ranges in aphids remain to be elucidated.

Host suitability relies on a number of factors, which could be based either at the plant surface or within plant tissues and cells (Powell et al., 2006). Prior to probing the leaf surface aphid behaviour can be influenced by a range of these factors including leaf colour, emitted volatile organic compounds and leaf surface components, such as epicuticular waxes or trichomes (Doring, 2014, Doring \& Chittka, 2007, Neal et al., 1990). Regardless of whether the aphid encounters a host or non-host plant species their specialised mouthparts, known as stylets, are utilised to probe into the plant tissue (Escudero-Martinez et al., 2017, Jaouannet et al., 2015, Powell et al., 2006). This probing behaviour is associated with the transmission of important plant viruses during both host and non-host interactions (Debokx \& Piron, 1990, Katis \& Gibson, 1985, Powell et al., 2006, Verbeek et al., 2010) which can substantially reduce crop yields (Perry et al., 2000). During interactions with susceptible plant species the 
aphid stylets penetrate the plant epidermis and move through the plant tissue towards the vascular bundle. During this process the stylets probe into adjacent plant cells, and saliva is secreted both in the apoplast and into probed cells along the stylet-pathway (Tjallingii, 2006, Tjallingii \& Esch, 1993). During compatible plantaphid interactions the aphid stylets are able to successfully puncture the sieve-tube elements to facilitate ingestion of phloem sap (Tjallingii, 1995, Tjallingii, 2006).

The aphid stylet-pathway through the plant tissue has been well-characterised during interactions with susceptible plants using the Electrical Penetration Graph (EPG) technique. This technique uses an electrical circuit to connect the aphid to the plant via a series of electrical probes, allowing distinction between different phases of the stylet pathway from obtained electrical waveforms which correlate with the position of the aphid stylet within plant tissue in real-time (Prado \& Tjallingii, 1994, Tjallingii, 1985a, Tjallingii, 1985b, Tjallingii \& Esch, 1993). Briefly, the aphid is attached to an electrical probe with gold wire, and a copper electrode is placed into the soil to incorporate the plant into the electrical system. Both the plant and the aphid electrodes are attached to a data-logger, which is read by computational software and the whole set-up is contained in a grounded Faraday cage (Mclean \& Kinsey, 1968, Tjallingii, 1978, Tjallingii, 1985a, Tjallingii, 1985b). Once the aphid probes the plant tissue the circuit closes and changes in electrical voltage are displayed as alternating waveforms which can be manually annotated using computational software and translated into time-series data (Tjallingii \& Esch, 1993). The biological relevance of the different waveforms that are detected by the EPG technique have been extensively analysed (Prado \& Tjallingii, 1994, Tjallingii, 1978, Tjallingii, 1985a, Tjallingii, 1985b). Waveforms associated with aphid probing are: waveform np, representing non-probing behaviour where the stylets are not in contact with the leaf 
51 surface; waveform $\mathrm{C}$, which begins upon stylet penetration of leaf tissue and is correlated with the intercellular apoplastic stylet pathway located at the epidermis or the mesophyll cell layers; waveform pd, associated with piercing of a plant cell which leads to a signal potential drop; waveform $F$, which reflects stylet mechanical/penetration difficulties; and waveform E1e, which represents extracellular saliva secretion into plant tissues other than phloem. Waveforms associated with vascular interactions and which provide intricate information at the aphid feeding site are: waveform $\mathrm{G}$, which represents aphids drinking from the xylem sap; waveform

E1, which is linked to aphid salivation into phloem before ingestion; and waveform E2, which corresponds to phloem sap ingestion (Alvarez et al., 2006). A graphical representation of examples of these waveforms, alongside the stylet activity during each, is shown in Fig. 1.

Although the EPG technique has mainly been used to study aphid interactions with susceptible and (partially-)resistant genotypes of host plant species, it also represents a suitable tool to explore how aphids interact with plants which are not natural hosts, including non-host and poor-host species. Indeed, EPG analyses of Brevicoryne brassicae Linnaeus (cabbage aphid) on host Brassicaceae and non-host Vicia faba showed that this aphid species was unable to reach the phloem when feeding on the non-host $V$. faba, despite probing the leaf surface (Garbys \& Pawluk, 1999). Also, epidermis and phloem factors contributed to resistance in different

71 legume species to different pea aphid biotypes (Schwarzkopf et al., 2013). By 72 characterising aphid probing and feeding behaviour across different aphid 73 interactions with non-/poor-host species we aim to generate a better understanding 74 of where associated resistance mechanisms reside. This in turn will facilitate 
important mechanistic studies to reveal the molecular determinants of plant immunity to aphids.

We previously showed that $M$. persicae, which is not a pest of barley, is able to feed and reproduce on this crop under controlled environment conditions, but to a lower extent than on a host species such as oil seed rape or Arabidopsis (EscuderoMartinez et al., 2017). On the contrary, Rhopalosiphum padi Linnaeus (bird cherryoat aphid) is a pest of barley but is unable to feed from, and therefore survive, on Arabidopsis (Jaouannet et al., 2015). However, in both the M. persicae-barley poorhost interaction and the $R$. padi-Arabidopsis non-host interaction probing of the leaf surface takes place (Escudero-Martinez et al., 2017, Jaouannet et al., 2015). In line with our previous findings, choice assays showed that both aphid species will settle on and interact with non-/poor-host plant species if given a choice, with $10 \%$ of aphids found on non-/poor-hosts after 24h. Using EPG analyses of $M$. persicae and R. padi on Arabidopsis and barley we explored differences in aphid probing and feeding behaviour during non-/poor-host versus host interactions. We show that resistance in the non-/poor-host interactions can reside in different plant cell layers, suggesting complex mechanisms may underlie plant immunity to aphids.

\section{Materials and Methods}

\section{Aphid rearing}

R. padi (JHI-JB, genotype G) (J. et al., Thorpe et al., 2018) was maintained on Hordeum vulgare cv Optic and $M$. persicae (JHI_genotype O) was maintained on Brassica napus (oilseed rape). All aphid species used in the experiments were maintained in growth chambers under controlled conditions $\left(18^{\circ} \mathrm{C} \pm 2^{\circ} \mathrm{C}, 16 \mathrm{~h}\right.$ of light). 


\section{Plant growth}

101 Barley plants (cv. Golden Promise) were pre-germinated in Petri dishes with wet filter paper for three days in the dark. Then, they were moved to a plant growth cabinet

103 under controlled conditions and grown for 7 days (growth stage 1.10, determined 104 using the staging key (Zadoks et al., 1974)) until the EPG experiments. Arabidopsis 105 thaliana Col-0 plants were sown directly in soil; the seeds were stratified for 3 days at $1064^{\circ} \mathrm{C}$ and placed in the growth cabinet for $4-5$ weeks before use in experiments 107 (growth stage 1.10 to 3.90, determined using the Boyes growth key (Boyes et al., 108 2001)). The cabinet conditions for Arabidopsis were 8 hours of light (125 $\mu$ mol 109 photons $\left./ \mathrm{m}^{2} . \mathrm{s}\right)$, at $22{ }^{\circ} \mathrm{C}$ and $70 \%$ humidity. The cabinet conditions for barley were 8 110 hours of light $(150 \mu \mathrm{mol}$ photons $/ \mathrm{m} 2 . \mathrm{s})$, at $20^{\circ} \mathrm{C}\left(+-2^{\circ} \mathrm{C}\right)$.

\section{Aphid choice experiment}

112 Aphid choice tests were devised to investigate the host plant preference of $R$. padi 113 and $M$. persicae. Three choice test assays were developed: one using 50 R. padi 114 aphids, a second using $50 \mathrm{M}$. persicae aphids, and a third using a mixed species 115 population (25 R. padi, 25 M. persicae). For each assay, fifty aphids (mixed aged: $2^{\text {nd }}$ 116 instar - apterous adult) were placed on a sheet of tissue paper and were placed in 117 the centre of a Perspex cage halfway between two plants (one Arabidopsis, one 118 barley). Aphids were $90 \mathrm{~mm}$ away from both plants and the two plants were $180 \mathrm{~mm}$ 119 apart. Bamboo sticks served as bridges from the cage bottom (where the aphids 120 were placed) to each plant, with additional bamboo sticks acting as bridges between 121 the two plants, similar to the set-up used by Nowak and Komor (Nowak \& Komor, 122 2010). Once the aphids were placed between the plants and the ladders were 123 positioned, the cages were closed and the proportion of aphids present on the host, 124 non-/poor-host, or which had not settled were scored three and 24 hours later. 
125 Choice assays were carried out in growth chambers under controlled conditions

$126\left(18^{\circ} \mathrm{C} \pm 2^{\circ} \mathrm{C}, 16 \mathrm{~h}\right.$ of light $)$.

128 Choice tests were carried out simultaneously in separate Perspex cages (440 $\mathrm{mm} \mathrm{x}$

$129340 \mathrm{~mm} \times 390 \mathrm{~mm}$ ). For each replicate the assignment of aphid mixture (R. padi, $M$.

130 persicae, or mixed) to cage $(1,2$, or 3 ) and the position (1 or 2 ) of Arabidposis and 131 barley within each cage was randomly assigned. Seven replicates were collected for 132 each aphid mixture. The proportion of aphids detected on each plant were modelled 133 in response to plant type (Host, non-/poor-host, or not settled), aphid mixture $(R$. 134 padi, $M$. persicae, mixed species), time-point (three hours and 24 hours) and all 135 interactions using a linear mixed effects model. Cage and block were included as 136 random factors, the model was simplified using manual backward stepwise model 137 selection, and fitted-residual plots were observed at each stage to assess model 138 suitability. Models were analysed using a $x^{2}$ Analysis of Deviance Test. Differences in 139 the Least Squares Mean with Tukey correction for multiple comparison was used as 140 a post-hoc test. Data were analysed in $R$ Studio v. 1.0.143 running R v. 3.4.3 (R Core 141 Team, 2017) with additional packages car v.2.1-4 (Weisberg \& Fox, 2011), Ime4 v.1.1-13, and Ismeans v.2.27-62 (Lenth, 2016).

\section{Electrical penetration graph (EPG) analyses}

145 The probing and feeding behaviour of $R$. padi and $M$. persicae on different plant 146 species was assessed using the Electrical Penetration Graph technique (Tjallingii, 147 1995) on a Giga-4 DC-EPG device with 1 Giga $\Omega$ resistance (EPG Systems, The 148 Netherlands). We used a randomized block design for all EPG experiments 149 performed here. Aphids were connected to a copper electrode with a golden wire (20 
$150 \mu \mathrm{m}$ diameter), attached at the aphid dorsum and connected to the electrode with

151 water-based silver glue. Aphids were lowered onto either an Arabidopsis or barley

152 leaf approximately 1-1.5 hr after being removed from culture, depending on the

153 treatment, and feeding behaviour was recorded over a $6 \mathrm{~h}$ period. Three recordings

154 were taken simultaneously. Each experiment was initiated between 10-12 am and

155 the experiment was performed over a 6-month period, with 18 host and 17 non-host

156 replicates for $R$. padi and 23 host and 28 poor-host replicates for M. persicae. Data

157 were acquired using the Stylet+ D software package version v.01.28 and annotated

158 manually using the Stylet+ A v.01.30 software (EPG-Systems, The Netherlands).

159 Obtained waveforms were annotated with one of the following signals: no penetration

160 (np), stylet penetration into the epidermal and mesophyll tissue (pathway/C phase),

161 cellular punctures during the $\mathrm{C}$ phase $(\mathrm{pd})$, watery salivation into sieve elements

162 (E1), ingestion of phloem sap (E2), derailed stylet mechanics/stylet penetration

163 difficulties (waveform F), xylem ingestion (waveform G), or extracellular saliva 164 secretion into mesophyll (E1e) (Alvarez et al., 2006, Tjallingii, 1995). Annotated 165 waveforms were converted into time-series data using the excel macro developed by 166 Dr Schliephake (Julius Kühn-Institut); these converted parameters were used for 167 statistical analysis. Parameters used for comparisons in these experiments are 168 described by Giordanengo et al. (Giordanengo, 2014), and include total time of 169 probing, number of probes, duration of phloem sap ingestion, and duration of xylem 170 sap ingestion, a total of 97 parameters were measured. Statistical analyses were 171 performed in $\mathrm{R}$ Studio running $\mathrm{R}$ v. 3.2.3. (R Core Team, 2017) using the Wilcoxon rank test, a significance threshold of 0.05 was used. 


\section{Results}

\section{Aphids preferentially settle on their host plant}

We used aphid choice assays to examine the host plant preference of

Rhopalosiphum padi and Myzus persicae. We monitored the settling behaviour of $R$. (non-host), and of a mixed species population containing R. padi and M. persicae. populations assessed $(t=-9.48 ; p=<0.001)$ with the number of unsettled aphids decreasing $(t=8.30 ; p=<0.001)$. However, approximately $10 \%$ of aphids were found mixture was observed (Table 1), indicating that the presence of additional aphid species did not influence aphid behaviour.

The Arabidopsis- $R$. padi non-host interaction is characterised by long noprobing periods and difficulties in locating the vascular tissues

We employed the Electrical Penetration Graph (EPG) technique to compare the

196 feeding behaviour of $R$. padi on barley (host) with Arabidopsis (non-host) and of $M$. persicae on Arabidopsis (host) with barley (poor-host) over a six hour period in order to identify the tissue layers involved in non-host and poor-host resistance against aphids. We assessed 97 feeding parameters in total, 71 of these were altered during 
200 feeding on non/poor-host plants compared with feeding patterns on host plants

201 (Table S1) with 26 parameters remaining unaffected (Table S2).

202 The majority of feeding parameters that differed between $R$. padi feeding on host

203 compared with non-host plants were related to stylet probing of the plant tissue and

204 interactions with the plant vasculature (Fig. 3). In general, probing parameters that

205 differed for $R$. padi when interacting with non-host versus host plants were non206 probing periods, number of stylet probes into plant tissue, and time spent in the 207 epidermal/mesophyll cells (C phase) (Fig. 3A; Table S1).

208 During non-host interactions with Arabidopsis, the total time the aphids were not 209 probing plant tissue during the $6 \mathrm{~h}$ recording was 2.5 times greater $(4889 \mathrm{~s})$ than the 210 host interactions (1767s) (Fig. 3A; Table S1; W = 33.00; $p=<0.001$ ). However, the 211 overall number of stylet probes into plant tissue was higher on non-host plants (18) 212 than host plants (8) (Fig. 3A; Table S1; W $=52.50, p=0.001$ ). Although the total 213 number of $\mathrm{C}$ phases (stylet activity at the epidermis/mesophyll, including a return to 214 C phase following stylet interactions in the vasculature) was not significantly different 215 between non-host and host interactions, the overall time spent in the 216 epidermis/mesophyll (C phase) was over two times longer for the non-host (14128s) 217 compared with host interactions (6237s) (Fig. 2A; Table S1; W = 37.00; $p=<0.001$ ).

218 All the vascular-related parameters (G, E1 salivation and E2 ingestion phases) 219 measured for $R$. padi were significantly reduced during non-host interactions 220 compared with host interactions (Fig. 3B; Table S1). This included a two-fold 221 reduction in the number of xylem ingestion ( $G$ phase) events during the non-host 222 interaction (0.24 times) compared with the host interaction (0.50 times) (Fig. 3B; 223 Table $S 1 ; \mathrm{W}=2.28 .50 ; p=0.001$ ) alongside a significant decrease in the total length 224 of xylem ingestion, 1021s for non-host compared with 1483s for host plants (Fig. 3B; 
225 Table $\mathrm{S} 1 ; \mathrm{W}=221.50 ; \mathrm{p}=0.003)$. We also observed significantly fewer salivation

226 events (E1 phase) during the non-host interaction (0.18 events) compared with the

227 host interaction (3.67 events; $W=282.00 ; p=<0.001$ ), with salivation events five-fold

228 shorter during the non-host interaction (18s) compared with the host interaction (93s)

229 (Fig. 3B; Table S1; W = 278.00; $p=<0.001$ ). Ingestion of phloem sap (E2 phase)

230 was rarely observed during the non-host interaction (0.06 times) compared with the

231 host interaction ( 3 times; $W=285.00 ; p=<0.001$ ), and the total duration of this

232 ingestion period was greatly reduced on non-host plants (19s) compared with host

233 plants (10030s, or 2.78 hours) (Fig. 3B; Table S1; W $=288.00 ; p=<0.001$ ).

The barley-M. persicae poor-host interaction is characterised by a lack of sustained phloem ingestion

237 The majority of feeding parameters that differed between $M$. persicae feeding on host compared with poor-host plants were primarily related to interactions within the plant vasculature, specifically a decrease in interactions with the phloem and an increase in interactions with the xylem (Fig. 4; Table S1). In general, this involved a decrease

241 in the ability to locate the phloem and initiate ingestion of phloem sap. When feeding 242 on poor-host plants there was a significant increase in the number of probes made 243 into the plant tissue by aphids (19) compared with the number of probes made into 244 host plants (16) (Fig. 3A; Table S1; W = 186.00; $p=0.024)$. However, the total length 245 of time aphids probed into plant tissue, the number of pathway (C) phase events, and 246 the total time spent within the pathway (C) phase was similar for the host and poor247 host interactions (Fig. 4A)

248 Aphid stylet activities related to the vascular parameters ( $G$ - xylem, E1 - phloem salivation, and E2 - phloem ingestion) were different between host and poor-host 
250 interactions (Fig. 4B; Table S1). The number of times that $M$. persicae reached the

251 xylem ( $G$ phase) during the poor-host interaction was higher (1.33 times; $W=$ $252133.50 ; p=<0.001)$ and the total time of xylem ingestion was longer $(2321 \mathrm{~s} ; \mathrm{W}=$ 253 142.50; $p=<0.001$ ) than during the host interaction, where aphids reached the xylem 2540.30 times and spent a total of 691s ingesting xylem sap (Fig. 4B; Table S1). For the 255 E1 salivation phase the number and duration of events was reduced during the poor256 host interaction, 1.73 events $(\mathrm{W}=5.28 ; \mathrm{p}=<0.001)$ with a total length of time spent 257 salivating into the phloem of 562 s $(W=500.00 ; p=<0.001)$, compared with the host 258 interaction (7 events with a time length of 652s) (Fig. 4B; Table S1).

M. persicae showed limited ingestion periods during the poor-host compared with host interactions. The number of E2 phases and their length was greatly reduced on poor-host plants, 0.53 events $(\mathrm{W}=552.50 ; \mathrm{p}=<0.001)$ with a 40 -fold decrease in the

262 total time spent ingesting phloem (126s; $W=573.50 ; p=<0.001$ ), compared with 263 host plants (5.7 events with a total length of 5064s) (Fig. 4B; Table S1). Moreover, on 264 the poor-host sustained phloem ingestion was severely lacking, and aphids spent 265 only 49s in the E2 ingestion phase on poor-host plants $(W=520.00 ; p=<0.001)$ with 266 events being nearly absent, 0.07 events $(W=515.00 ; p=<0.001)$. In contrast, 267 aphids spent 4322 s in the E2 sustained ingestion phase on host plants over 2.1 268 events during the $6 \mathrm{~h}$ recording (Fig. 4B; Table 1). Therefore, the M. persicae poor269 host interaction features substantially reduced phloem ingestion.

\section{Discussion}

272 The overall aim of this study was to gain insight into where resistances against 273 aphids may reside within the plant tissue during host versus non/poor-host 274 interactions by analysing aphid probing and feeding behaviour. We showed that 
275 when given a choice aphids do interact with non-/poor-host plants under controlled conditions, and we further explored these interactions using EPG analyses. Common

277 features of the non-host and poor-host interactions were an increased number of 278 probes and longer no-probing periods. Importantly, our data showed differences

279 between $R$. padi and $M$. persicae probing and feeding behaviour on the non-/poor280 host plants. During the R. padi-Arabidopsis (non-host) interaction the aphids only occasionally reached the vascular tissues. On the contrary, during the $M$. persicaebarley interaction (poor-host) aphids successfully reached the vascular tissue and could ingest xylem and phloem, however prolonged periods of phloem ingestion were inhibited. Based on the data generated here for $M$. persicae and $R$. padi we propose a model wherein poor- and non-host plant resistances against these aphid species may reside within the phloem and mesophyll cell layers, respectively (Fig. 5).

During the $R$. padi-barley interaction (host interaction) the aphids spend less time probing and in the pathway $(\mathrm{C})$ phase and readily reach the phloem where salivation and phloem sap ingestion occurs for several hours (Fig. 5A). Occasionally, aphids ingest xylem, which is thought to be important in coping with osmotic effects associated with ingestion of large amounts of phloem sap (Pompon et al., 2010,

292 Spiller et al., 1990). In contrast, during the R. padi - Arabidopsis interaction (non-host interaction) aphids exhibit altered probing behaviour, including an increase in the

294 number of plant probes alongside a decrease in the total time probing into plant

295 tissue. Additionally, R. padi shows an extended stylet pathway phase, and only rarely 296 does the aphid reach the Arabidopsis phloem or xylem (Fig. 5B). On the occasions 297 where the R. padi stylets reach the vascular tissue during non-host interactions the 298 ingestion of phloem and xylem sap is ineffective, in line with this aphid being unable 299 to survive on Arabidopsis (Jaouannet et al., 2015). 
300 Interestingly, R. padi spent less time probing into plant tissue during the non-host

301 interaction. However, during these probes aphids spent an increased time interacting with the mesophyll tissue during the non-host interaction than the host interaction,

303 including an increase in the total time spent in the pathway $(C)$ phase. This indicates 304 that non-host resistance could potentially reside in the mesophyll tissue as the aphids 305 struggled to probe beyond this layer and access to the vascular tissue was limited 306 (Fig. 5B), as further indicated by the increased time required for aphids to reach the 307 phloem during non/poor-host interactions compared with the host interactions.

308 Further research will be needed to further understand the mechanisms underlying 309 Arabidopsis non-host resistance to R. padi, and to investigate the potential 310 involvement of specific recognition receptors within the mesophyll cell layer.

311 Interestingly, the NADPH oxidase AtRbohF, involved in ROS (Reactive Oxygen 312 Species) production, a member of the LEA (Late Embryogenesis Abundant) family, 313 implicated in abiotic and biotic stress, as well as the VSP1 (Vegetative Storage 314 Protein 1), which is activated by jasmonate signalling, contribute to Arabidopsis non315 host resistance against $R$. padi (Jaouannet et al., 2015). Whether these genes act within the mesophyll cell layer to activate defences against aphids remains to be 317 determined.

319 The M. persicae-Arabidopsis (host) interaction, features short probing and pathway 320 times, and prolonged salivation and ingestion once the phloem is reached, as well as 321 occasional xylem drinking (Fig. 5C). In contrast, during the $M$. persicae-barley 322 interaction (poor-host interaction) aphids show increased probing but spend a similar 323 time in the stylet pathway phase as aphids on host Arabidopsis plants. The main 324 differences between the Arabidopsis (host) and barley (poor-host) interactions with 
M. persicae are reduced salivation in the phloem and relatively short periods of

326 phloem ingestion (less than 10 minutes) on barley (Fig. 5C and 5D). It is likely that this reduced phloem sap ingestion is responsible for the reduced $M$. persicae performance on barley (Escudero-Martinez et al., 2017, Ramirez \& Niemeyer, 2000). It is possible that $M$. persicae attempts to compensate for this reduced ingestion of phloem sap with increased xylem drinking, in line with the observation that aphid

331 starvation increases the xylem phase (Fig. 5D) (Ramirez \& Niemeyer, 2000).

332 Phloem resistance factors are related to the $\mathrm{E} 1$ salivation and $\mathrm{E} 2$ ingestion 333 parameters, and in particular ingestion phases shorter than 10 minutes (Alvarez et 334 al., 2006, Prado \& Tjallingii, 1997). Phloem-mediated defences against aphids 335 include the occlusion of sieve elements, which prevents aphids from ingesting 336 phloem sap (Dreyer \& Campbell, 1987, Medina-Ortega \& Walker, 2015, Will \& van 337 Bel, 2006). This phloem occlusion occurs upon callose deposition and formation of P338 protein plugs. The latter is thought to seal off the phloem upon damage and/or to 339 block the aphid food canal (Tjallingii, 2006, Will \& van Bel, 2006). Interestingly, PAD4 340 was found to be a component of phloem-based immunity against $M$. persicae in 341 Arabidopsis (Pegadaraju et al., 2007). However, no barley PAD4 (MLOC_1340) or 342 PAD4-related genes were up-regulated during the barley- $M$. persicae interaction 343 (Escudero-Martinez et al., 2017). However, our previous transcriptome analyses 344 showed induction of a barley gene encoding Phloem Protein 2-like (PP2), which is a 345 phloem specific lectin, with the induction being most pronounced during the barley- $M$. 346 persicae interaction (Escudero-Martinez et al., 2017). Lectins have carbohydrate347 binding properties and function in cell communication, development, and plant 348 defence (Bellande et al., 2017). PP2 is a lectin highly abundant in the phloem and 349 accumulates in damaged phloem sieve pores to form protective plugs (Read \& 
350 Northcote, 1983). Overexpression of AtPP2 in Arabidopsis leads to reduced $M$. 351 persicae feeding suggesting PP2 may contribute to defences against aphids (Zhang 352 et al., 2011), possibly by interfering with aphid digestion in the midgut (Kehr, 2006).

353 The very infrequent phloem sap ingestion we observed might reflect a rejection of the

354 sieve element, possibly due to the presence of a deterrent factor in the phloem sap 355 (Mayoral et al., 1996). Indeed, lectins, including PP2-like proteins, have been shown 356 to have deterrent activities and insecticidal activities against M. persicae (Jaber et al., 357 2010, Sauvion et al., 1996, Zhang et al., 2011). Whether barley phloem-lectins like PP2 indeed contribute to phloem-based defences of barley against M. persicae needs to be further tested.

It is important to note that the EPG experimental set-up was of a no-choice nature

361 (i.e. aphids were placed on the plants) and that additional plant resistance 362 components that affect aphid choice may play a role in the interactions studied here 363 (Escudero-Martinez et al., 2017, Powell et al., 2006). For example, we previously 364 showed that the black cherry aphid (Myzus cerasi Fabricius), which infests cherry 365 trees as well as several herbaceous plants, displays only limited probing on non-host 366 barley plants, and does not settle on barley leaves (Escudero-Martinez et al., 2017), 367 pointing to a potential role of barley defences that act at the pre-probing level against 368 this aphid species (Nottingham et al., 1991). In addition, some plant induced volatile 369 compounds have been reported to be repellent to aphid pests and attractants of their 370 natural enemies (Dreyer \& Jones, 1981, Mallinger et al., 2011, Turlings \& Ton, 2006).

371 With limited genetic crop resistance available against aphids, identifying the 372 determinants of non/poor-host resistance is an important area of research that may 373 help the development novel crop protection strategies. Using a detailed assessment of aphid probing and feeding behaviour on different natural host and non-host 

manuscript.

species we show that resistances may reside in different cell layers depending on the plant species-aphid species interaction.

\section{Acknowledgements}

Dr. Freddy Tjallingii (EPG Systems, The Netherlands), Professor Alberto Fereres (CSIC, Spain) and Professor Gregory Walker (University of California, Riverside, USA) for providing EPG training, and additional thanks to Dr Tjallingii for helpful comments on non-host EPG waveforms. We also thank Dr. Nicholas Birch (The James Hutton Institute) for allowing us to use the EPG equipment. This work was support by the European Research Council (310190-APHIDHOST to JIBB), and the James Hutton Institute and Universities of Aberdeen and Dundee through a Scottish Food Security Alliance (Crops) PhD studentship to DJL.

\section{Competing interests}

The author(s) declare no competing interests.

\section{Author contributions}

JIBB, CEM and DJL conceived and designed the experiments, CEM and DJL performed the experiments, JIBB, CEM and DJL analysed the data, JIBB and CEM wrote the manuscript with input from DJL. All authors read and approved the final 
bioRxiv preprint doi: https://doi.org/10.1101/372839; this version posted May 30, 2019. The copyright holder for this preprint (which was

not certified by peer review) is the author/funder, who has granted bioRxiv a license to display the preprint in perpetuity. It is made available under aCC-BY-NC-ND 4.0 International license.

\section{Tables}

Table 1: Statistical results of the choice test assay

\begin{tabular}{|c|c|c|}
\hline Response variable & $\begin{array}{c}\text { Test Statistic (degrees of } \\
\text { freedom) }\end{array}$ & p-value \\
\hline Plant Type & $\mathrm{X}_{(2)}^{2}=532.65$ & $P=<0.001$ \\
\hline Aphid Mixture & $X^{2}{ }_{(2)}=0.01$ & $P=0.996$ \\
\hline Time-point & $\mathrm{X}_{(1)}^{2}=0.01$ & $P=0.949$ \\
\hline Plant Type x Aphid mixture & $\mathrm{X}^{2}{ }_{(4)}=5.43$ & $P=0.245$ \\
\hline Plant Type x Time-Point & $X^{2}{ }_{(2)}=162.06$ & $P=<0.001$ \\
\hline Aphid Mixture x Time-Point & $\mathrm{X}^{2}{ }_{(2)}=0.01$ & $P=0.996$ \\
\hline $\begin{array}{c}\text { Plant Type } x \text { Aphid Mixture } x \\
\text { Time-Point }\end{array}$ & $\mathrm{X}^{2}{ }_{(4)}=0.34$ & $P=0.986$ \\
\hline
\end{tabular}




\section{Figures}

A)

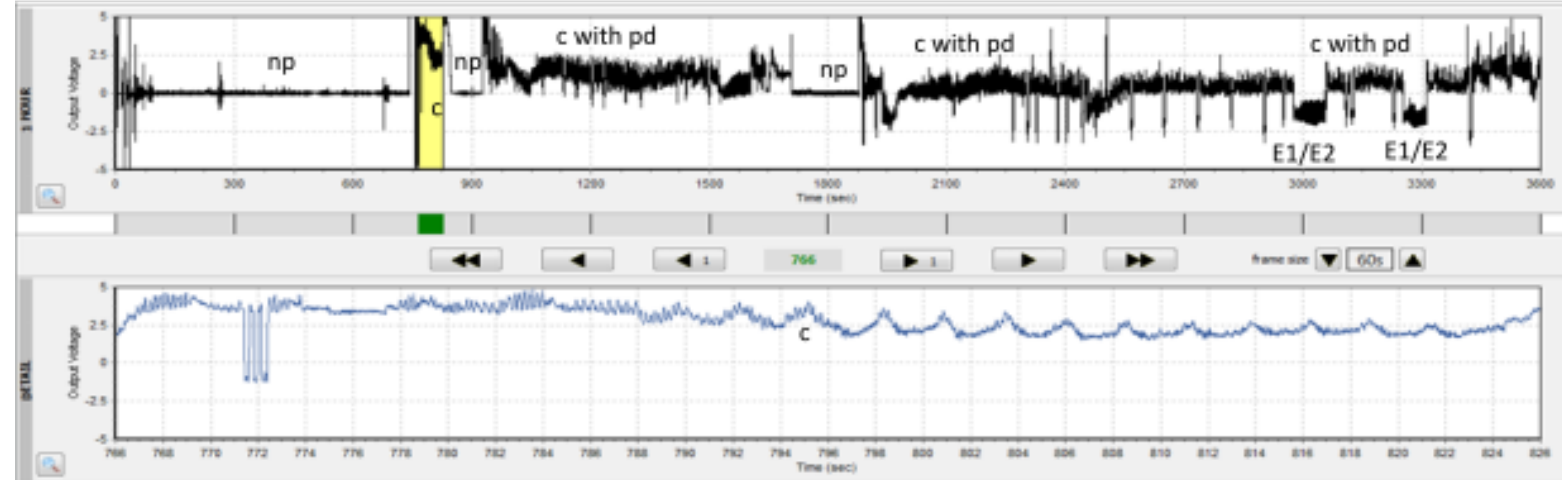

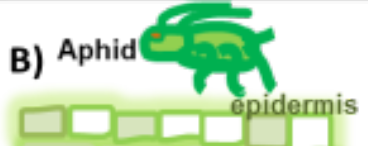

C) Aphid
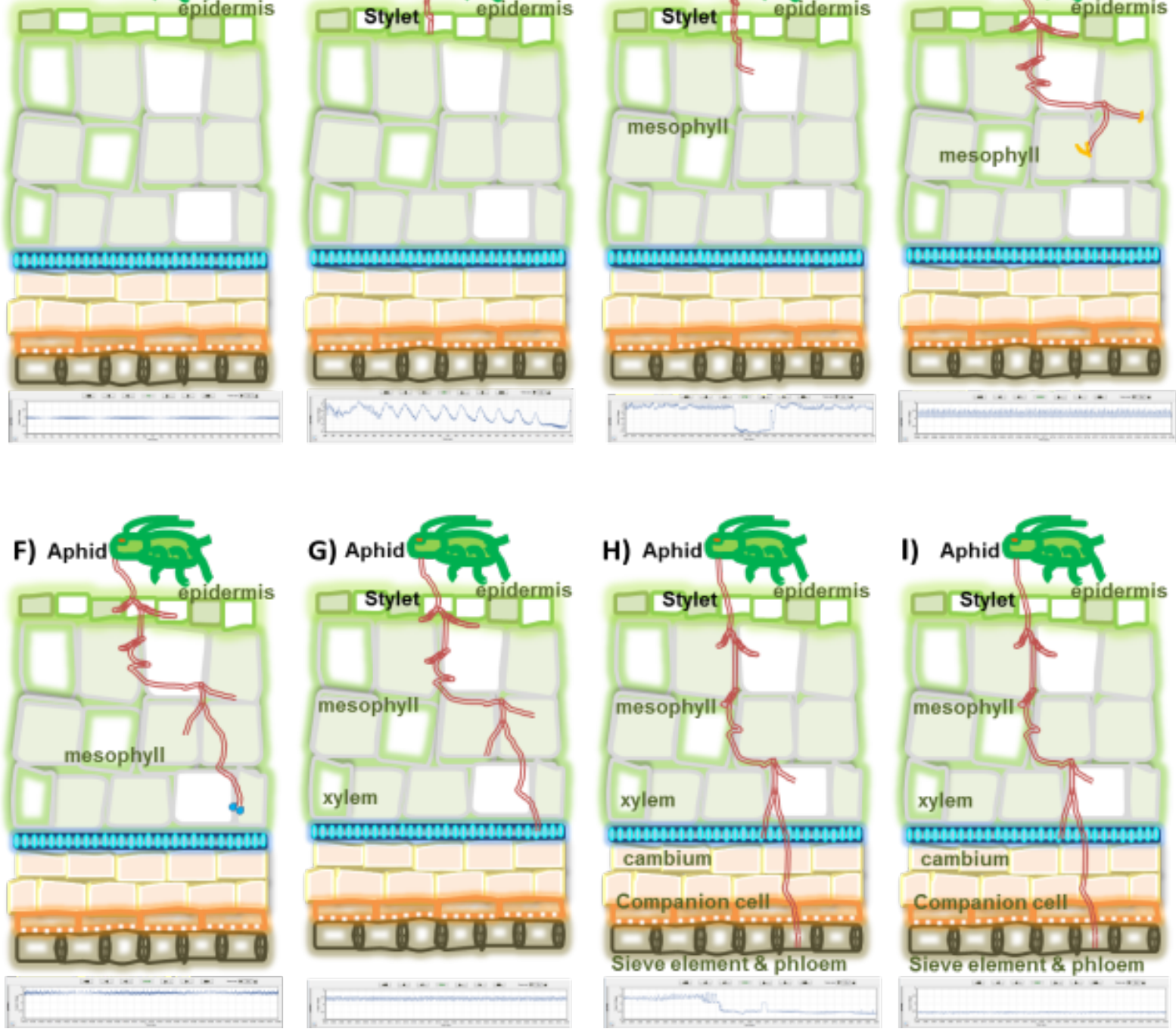

Figure 1. Graphical representation of aphid/stylet activities associated with each EPG waveform. 
(A) Example of aphid activity during $\mathrm{np}$ (non-probing) period, stylet is not in contact with leaf tissue.

(B) Initiation of pathway (C) phase - aphid stylet pierces leaf epidermis,

(C) Potential drop (pd) - aphid stylet penetrates adjacent plant cell

(D) Stylet penetration difficulties ( $F$ phase)

(E) Extracellular saliva secretion (E1e) phase - salivation into extracellular space.

(F) Xylem ingestion ( $G$ phase) - stylet penetrates vascular xylem cells to initiate xylem drinking.

(G) Salivation into phloem (E1 phase) - stylet penetrates sieve tube element and aphid initiates salivation into phloem sap.

(H) Phloem ingestion (E2 phase) - aphid begins passive ingestion of phloem sap. Also includes sustained phloem ingestion (sE2 phase) - a period of phloem sap ingestion lasting > 10 mins. 


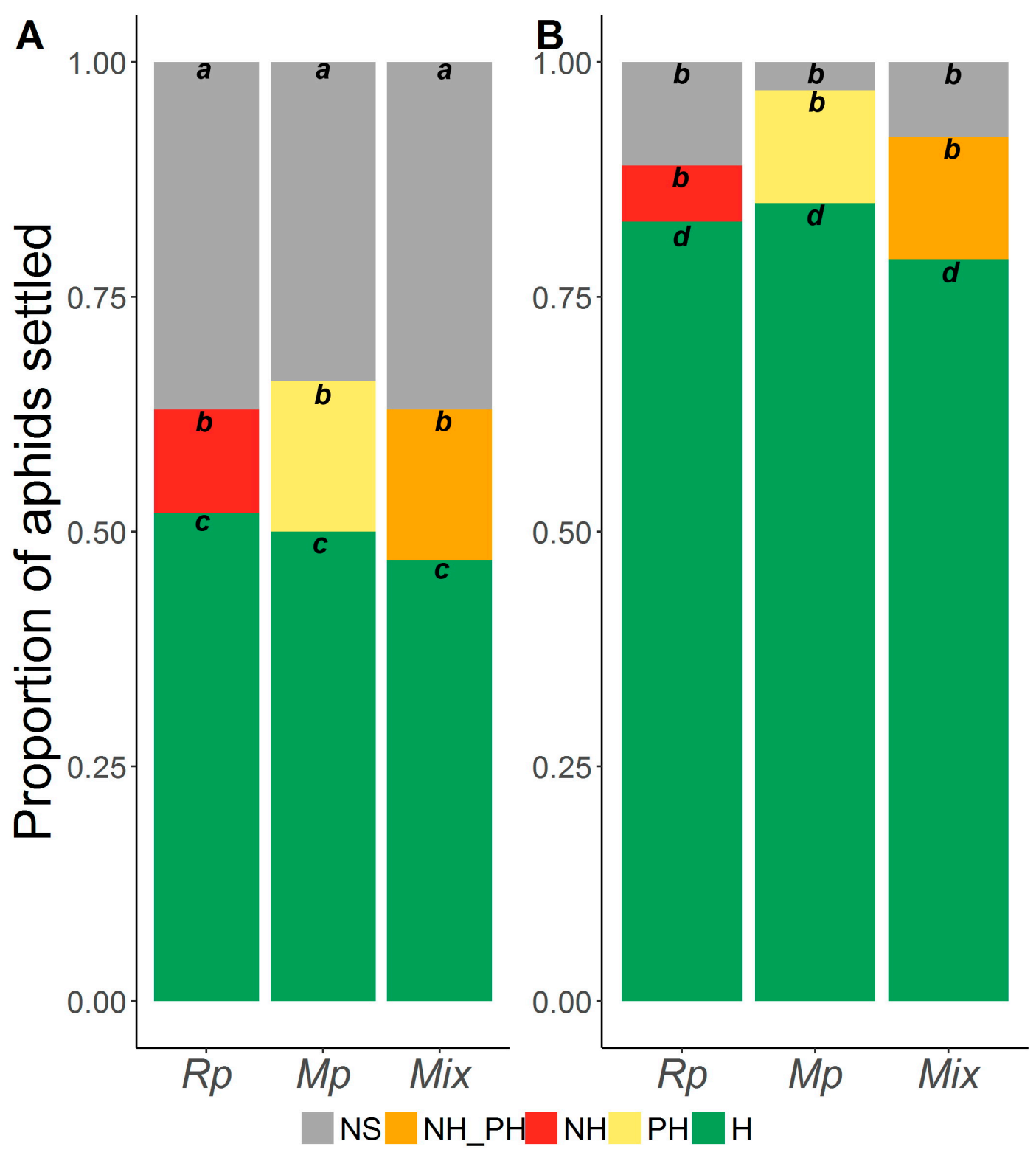

Figure 2. Stacked bar charts showing the settling behaviour of aphids in the choice experiment.

(A) Aphid settling after three hours

(B) Aphid settling after 24 hours

Graphs show the mean proportion of aphids from the R. padi (Rp), M. persicae (Mp), and the mixed species population (Mix) which had settled on the host plant $(\mathrm{H}$; green), the non-host plant $(\mathrm{NH}$; red), the poor-host plant $(\mathrm{PH}$; yellow), the non/poorhost plant (NH.PH; orange) or which has not settled (NS; grey). Letter under each 
bioRxiv preprint doi: https://doi.org/10.1101/372839; this version posted May 30, 2019. The copyright holder for this preprint (which was

not certified by peer review) is the author/funder, who has granted bioRxiv a license to display the preprint in perpetuity. It is made available under aCC-BY-NC-ND 4.0 International license.

bar indicate differences based on Least Squares Mean post-hoc analysis with Tukey correction. 
A

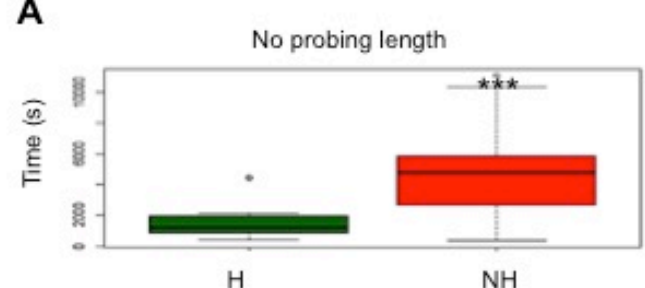

$\mathrm{H}$

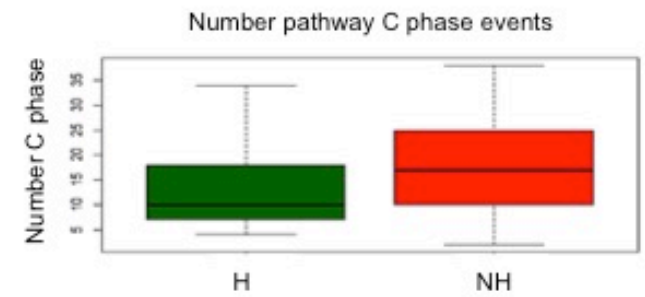

B
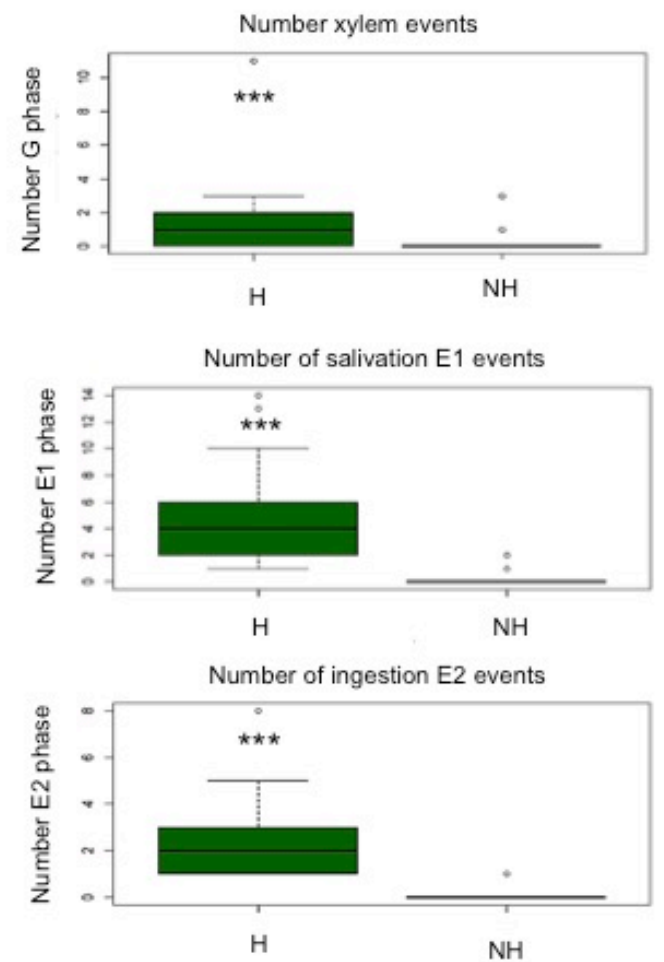
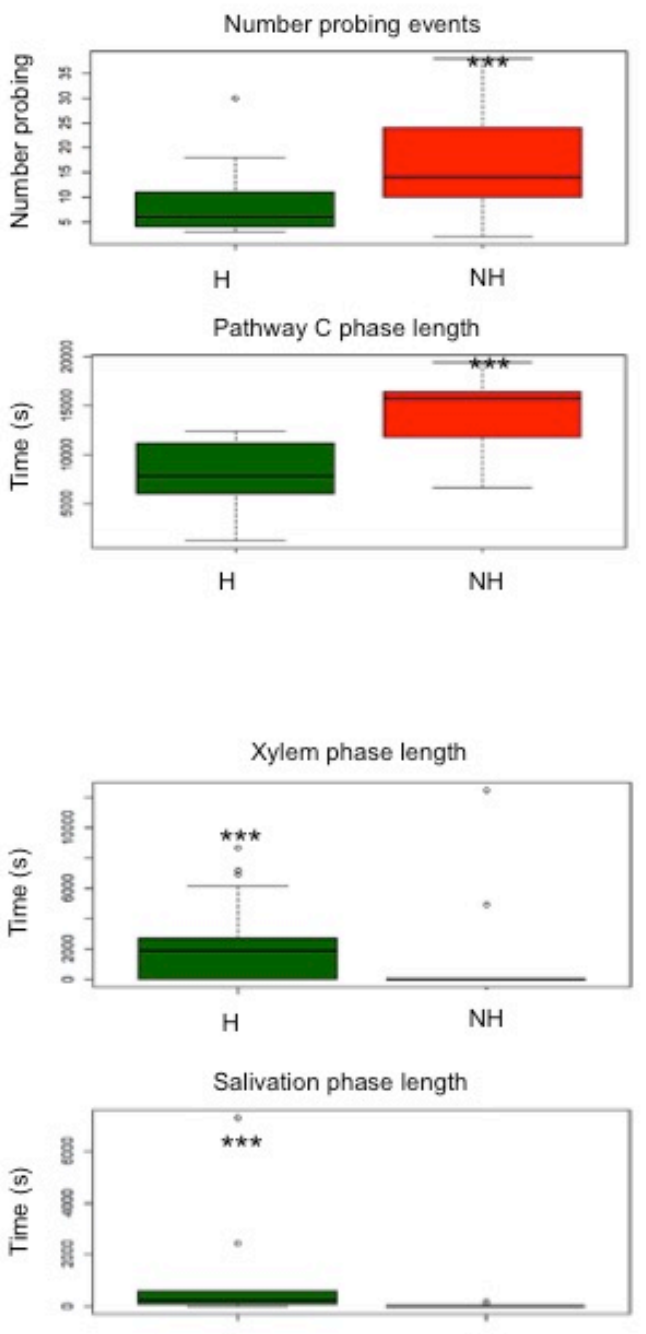

$\mathrm{NH}$

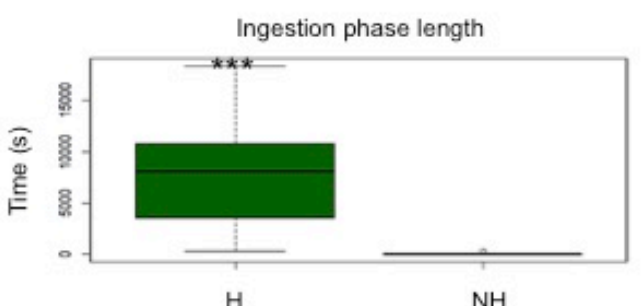

H

$\mathrm{NH}$

Figure 3. Box plots showing different EPG parameters associated with Rhopalosiphum padi-barley (host) and Rhopalosiphum padi-Arabidopsis (nonhost) interactions.

(A) Probing-related parameters: total number of probing events, total length of no probing time, total number of pathway (C) phase events, total length of pathway (C) phase time. 
(B) Vascular-related parameters: number of xylem ingestion ( $G$ phase) events, total length of xylem ingestion, number of salivation (E1 phase) events where aphid saliva is secreted into phloem sap, total length of salivation (E1 phase), number of phloem sap ingestion (E2 phase) events and total length of phloem sap ingestion (E2 phase). Green boxes indicate the host $(\mathrm{H})$ interaction and red boxes represent the non-host $(\mathrm{NH})$ interaction. $R$. padi on host plants was replicated 18 times and $R$. padi on nonhost plants was replicated 17 times. Significant differences between interactions were assessed by Wilcoxon non-parametric t-test $\left({ }^{*}=p \leq 0.05\right.$ and $\left.{ }^{* * *}=p \leq 0.01\right)$. 


\section{A}

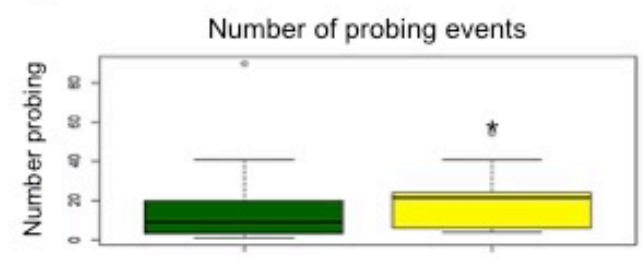

$\mathrm{H}$

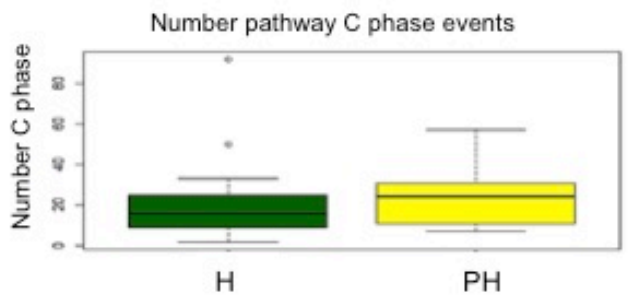

B
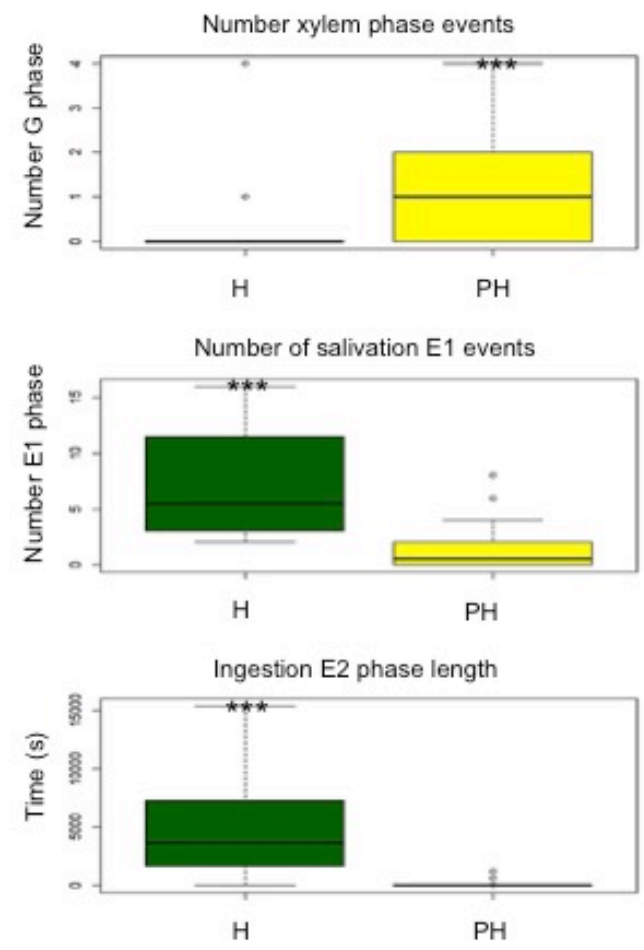

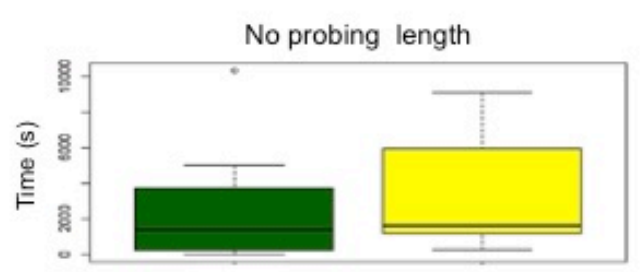

$\mathrm{PH}$

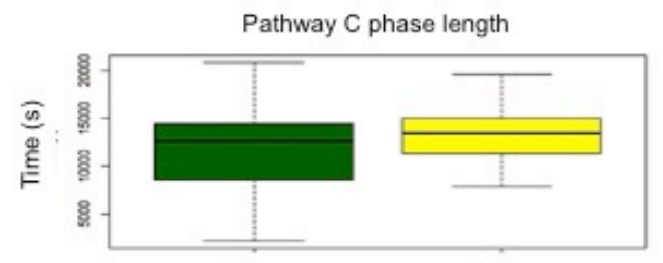

$\mathrm{PH}$
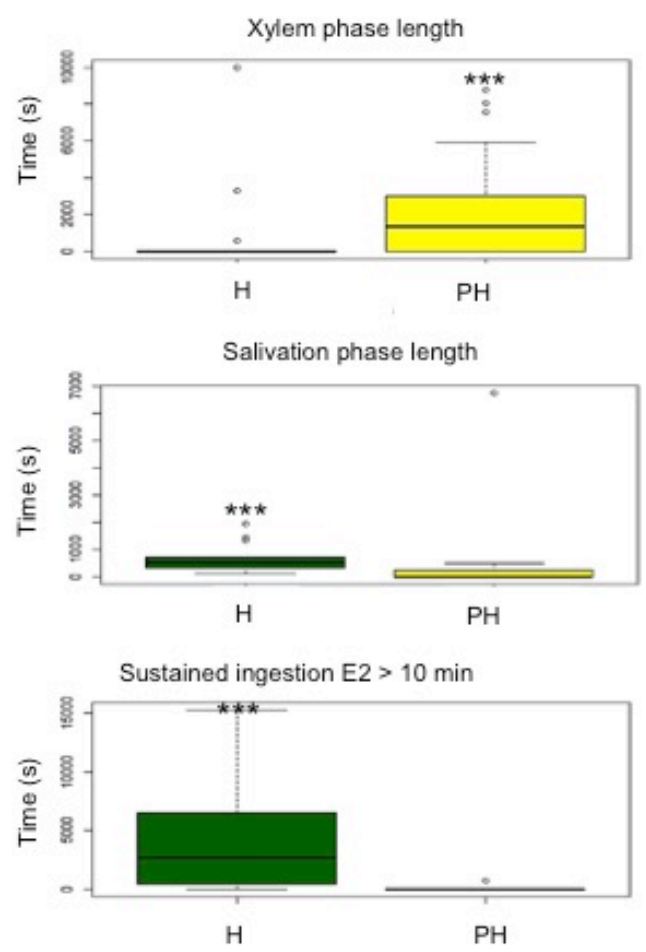

Figure 4: Box plots showing different EPG parameters in Myzus persicae interaction with a host (Arabidopsis) and a poor-host plant (barley).

(A) Probing-related parameters: total number of probing events, total length of no probing time, total number of pathway $(\mathrm{C})$ phase events, total length of pathway $(\mathrm{C})$ phase time. (B) Vascular-related parameters: number of xylem ingestion ( $G$ phase) events, total length of xylem ingestion, number of salivation (E1 phase) events where 
aphid saliva is secreted into phloem sap, total length of salivation (E1 phase), total length of phloem sap ingestion (E2 phase) and total length of sustained phloem sap ingestion (sE2 phase).

Green boxes indicate the host $(\mathrm{H})$ interaction and yellow boxes represent the poorhost $(\mathrm{PH})$ interaction. $M$. persicae on host plants was replicated 23 times and $M$. persicae on poor-host plants was replicated 28 times. Significant differences between interactions were assessed statistically by Wilcoxon non-parametric t-test $\left({ }^{*}=p \leq 0.05\right.$ and $\left.{ }^{* * *}=p \leq 0.01\right)$. 


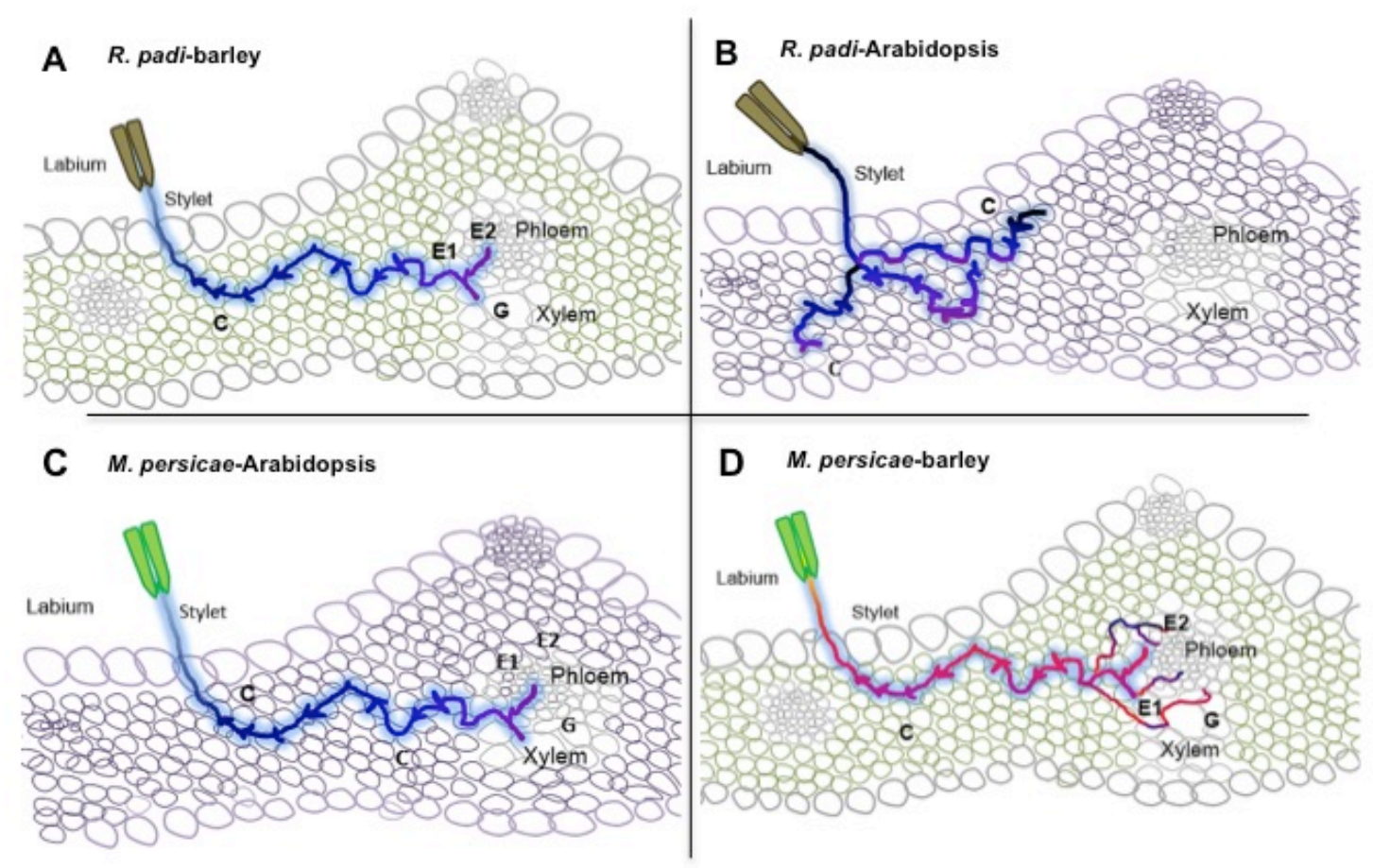

Figure 5. Model showing $R$. padi and M. persicae probing and feeding during host, poor-host and non-host plant interactions.

(A) During the host interaction (R. padi-barley), the aphids will probe the epidermal and mesophyll cells (pathway C phase), then will drink from the xylem or salivate and feed from the phloem, with feeding lasting for hours.

(B) During the non-host interaction (R. padi-Arabidopsis), the aphids will spend a long time not probing, and when probing eventually occurs the aphids remain in stylet pathway phase (in epidermis and mesophyll cell layers) most of the time and only occasionally will reach the vascular tissue, either xylem or phloem. No sustained ingestion of phloem sap takes place.

(C) During the host interaction ( $M$. persicae-Arabidopsis), the aphids will probe the epidermal and mesophyll cells (pathway C phase), then will drink from the xylem or salivate and feed from the phloem, with feeding taking place for hours.

(D) During the poor-host interaction (M. persicae-barley), the aphids show increased probing compared to the host interaction, while the stylet pathway phase (in 
epidermis and mesophyll cell layers) is similar to the interaction with the host plant. At the vascular level, long periods of time will be spent in the xylem, and eventually aphid will reach the phloem, salivate and ingest phloem sap. However, contrary to the host interaction, no sustained (>10 minutes) ingestion of phloem sap takes place.

\section{Supplementary Data}

Table S1. Results for all obtained Electrical penetration graph (EPG) parameters which were significantly different between host and non/poor-host feeding. Table displays the EPG parameter assessed, a description of the parameter, and the plant tissue layer involved. Results displayed are the mean and standard deviation (SD) for each aphid-plant combination for each parameter alongside the Wilcoxon test statistic (W value) and $p$ value for each pairwise host vs non/poor host comparison. $p$ values in bold represent values significantly different in both host vs non-host and host vs poor-host interactions, italicised $p$ values represent parameters which only differed in one combination. Average and standard deviation of the 97 electrical EPG parameters calculated for R. padi host (Rp_Hv) and non-host (Rp_At). Average and standard deviation of the 97 electrical EPG parameters calculated for M. persicae host (Mp_At) and poor-host (Mp_Hv). Calculations were made with summary statistics in Rstudio. The EPG list of parameters was taken from EPG systems: www.epgsystems.eu/files/List\%20EPG\%20variables.xls

Table S2: Results for all obtained Electrical penetration graph (EPG) parameters which were not significantly different between host and non/poor-host feeding. Table displays the EPG parameter assessed, a description of the parameter, and the plant tissue layer involved. Results displayed are the mean and standard deviation (SD) for each aphid-plant combination for each parameter alongside the Wilcoxon test 
statistic (W value) and $p$ value for each pairwise host vs non/poor host comparison. $p$ values in bold represent values significantly different in both host vs non-host and host vs poor-host interactions, italicised $p$ values represent parameters which only differed in one combination. Average and standard deviation of the 26 electrical EPG parameters calculated for R. padi host (Rp_Hv) and non-host (Rp_At). Average and standard deviation of the 97 electrical EPG parameters calculated for M. persicae host (Mp_At) and poor-host (Mp_Hv). Calculations were made with summary statistics in Rstudio. The EPG list of parameters was taken from EPG systems: www.epgsystems.eu/files/List\%20EPG\%20variables.xls 


\section{References:}

Alvarez, A.E., Tjallingii, W.F., Garzo, E., Vleeshouwers, V., Dicke, M. and Vosman, B. (2006) Location of resistance factors in the leaves of potato and wild tuber-bearing Solanum species to the aphid Myzus persicae. Entomologia Experimentalis Et Applicata, 121, 145-157.

Bellande, K., Bono, J.J., Savelli, B., Jamet, E. and Canut, H. (2017) Plant Lectins and Lectin Receptor-Like Kinases: How Do They Sense the Outside? International Journal of Molecular Sciences, 18.

Blackman R, E.V. (2000) Aphids on the world crops. p. 466. Wiley \& sons, Chichester.

Boyes, D.C., Zayed, A.M., Ascenzi, R., Mccaskill, A.J., Hoffman, N.E., Davis, K.R. and Gorlach, J. (2001) Growth stage-based phenotypic analysis of arabidopsis: A model for high throughput functional genomics in plants. Plant Cell, 13, 1499-1510.

Debokx, J.A. and Piron, P.G.M. (1990) RELATIVE EFFICIENCY OF A NUMBER OF APHID SPECIES IN THE TRANSMISSION OF POTATO VIRUS-YN IN THE NETHERLANDS. Netherlands Journal of Plant Pathology, 96, 237-246.

Doring, T.F. (2014) How aphids find their host plants, and how they don't. Annals of Applied Biology, 165, 3-26.

Doring, T.F. and Chittka, L. (2007) Visual ecology of aphids-a critical review on the role of colours in host finding. Arthropod-Plant Interactions, 1, 316.

Dreyer, D.L. and Campbell, B.C. (1987) CHEMICAL BASIS OF HOST-PLANT RESISTANCE TO APHIDS. Plant Cell and Environment, 10, 353-361.

Dreyer, D.L. and Jones, K.C. (1981) FEEDING DETERRENCY OF FLAVONOIDS AND RELATED PHENOLICS TOWARDS SCHIZAPHIS-GRAMINUM AND MYZUS-PERSICAE - APHID FEEDING DETERRENTS IN WHEAT. Phytochemistry, 20, 2489-2493.

Escudero-Martinez, C.M., Morris, J.A., Hedley, P.E. and Bos, J.I.B. (2017) Barley transcriptome analyses upon interaction with different aphid species identify thionins contributing to resistance. Plant Cell and Environment, 40, 2628-2643.

Garbys, B. and Pawluk, M. (1999) Acceptability of different species of Brassicaeceae as hosts for the cabbage aphid. Entomologia Expertimentalis et Applicata, 91, 105-109.

Giordanengo, P. (2014) EPG-Calc: a PHP-based script to calculate electrical penetration graph (EPG) parameters. Arthropod-Plant Interactions, 8, 163-169.

J., L.D., B., B.J.I., A., V.T. and J., K.A. The price of protection: a defensive endosymbiont impairs nymph growth in the bird cherry-oat aphid, Rhopalosiphum padi. Insect Science, $\mathbf{0}$.

Jaber, K., Haubruge, E. and Francis, F. (2010) Development of entomotoxic molecules as control agents: illustration of some protein potential uses and limits of lectins. Biotechnologie Agronomie Societe Et Environnement, 14, 225-241.

Jaouannet, M., Morris, J.A., Hedley, P.E. and Bos, J.I. (2015) Characterization of Arabidopsis Transcriptional Responses to Different 
Aphid Species Reveals Genes that Contribute to Host Susceptibility and Non-host Resistance. PLoS Pathog, 11, e1004918.

Katis, N. and Gibson, R.W. (1985) TRANSMISSION OF POTATO VIRUS-Y BY CEREAL APHIDS. Potato Research, 28, 65-70.

Kehr, J. (2006) Phloem sap proteins: their identities and potential roles in the interaction between plants and phloem-feeding insects. Journal of Experimental Botany, 57, 767-774.

Lenth, R.V. (2016) Least-Squares Means: The R Package Ismeans. Journal of Statistical Software, 69, 1-33.

Mallinger, R.E., Hogg, D.B. and Gratton, C. (2011) Methyl Salicylate Attracts Natural Enemies and Reduces Populations of Soybean Aphids (Hemiptera: Aphididae) in Soybean Agroecosystems. Journal of Economic Entomology, 104, 115-124.

Mayoral, A.M., Tjallingii, W.F. and Castanera, P. (1996) Probing behaviour of Diuraphis noxia on five cereal species with different hydroxamic acid levels. Entomologia Experimentalis Et Applicata, 78, 341-348.

Mclean, D.L. and Kinsey, M.G. (1968) Probing Behavior of Pea Aphid Acyrthosiphon Pisum .2. Comparisons of Salivation and Ingestion in Host and Non-Host Plant Leaves. Annals of the Entomological Society of America, 61, 730-\&.

Medina-Ortega, K.J. and Walker, G.P. (2015) Faba bean forisomes can function in defence against generalist aphids. Plant Cell and Environment, 38, 1167-1177.

Moran, N.A. (1992) THE EVOLUTION OF APHID LIFE-CYCLES. Annual Review of Entomology, 37, 321-348.

Neal, J.J., Tingey, W.M. and Steffens, J.C. (1990) SUCROSE ESTERS OF CARBOXYLIC-ACIDS IN GLANDULAR TRICHOMES OF SOLANUMBERTHAULTII DETER SETTLING AND PROBING BY GREEN PEACH APHID. Journal of Chemical Ecology, 16, 487-497.

Nottingham, S.F., Hardie, J., Dawson, G.W., Hick, A.J., Pickett, J.A., Wadhams, L.J. and Woodcock, C.M. (1991) BEHAVIORAL AND ELECTROPHYSIOLOGICAL RESPONSES OF APHIDS TO HOST AND NONHOST PLANT VOLATILES. Journal of Chemical Ecology, 17, 1231-1242.

Nowak, H. and Komor, E. (2010) How aphids decide what is good for them: experiments to test aphid feeding behaviour on Tanacetum vulgare (L.) using different nitrogen regimes. Oecologia, 163, 973-84.

Pegadaraju, V., Louis, J., Singh, V., Reese, J.C., Bautor, J., Feys, B.J., Cook, G., Parker, J.E. and Shah, J. (2007) Phloem-based resistance to green peach aphid is controlled by Arabidopsis PHYTOALEXIN DEFICIENT4 without its signaling partner ENHANCED DISEASE SUSCEPTIBILITY1. Plant Journal, 52, 332-341.

Perry, K.L., Kolb, F.L., Sammons, B., Lawson, C., Cisar, G. and Ohm, H. (2000) Yield effects of Barley yellow dwarf virus in soft red winter wheat. Phytopathology, 90, 1043-1048.

Pompon, J., Quiring, D., Giordanengo, P. and Pelletier, Y. (2010) Role of xylem consumption on osmoregulation in Macrosiphum euphorbiae (Thomas). Journal of Insect Physiology, 56, 610-615. 
Powell, G., Tosh, C.R. and Hardie, J. (2006) Host plant selection by aphids: behavioral, evolutionary, and applied perspectives. Annu Rev Entomol, 51, 309-30.

Prado, E. and Tjallingii, W.F. (1994) APHID ACTIVITIES DURING SIEVE ELEMENT PUNCTURES. Entomologia Experimentalis Et Applicata, 72, 157-165.

Prado, E. and Tjallingii, W.F. (1997) Effects of previous plant infestation on sieve element acceptance by two aphids. Entomologia Experimentalis Et Applicata, 82, 189-200.

Ramirez, C.C. and Niemeyer, H.M. (2000) The influence of previous experience and starvation on aphid feeding behavior. Journal of Insect Behavior, 13, 699-709.

Read, S.M. and Northcote, D.H. (1983) SUBUNIT STRUCTURE AND INTERACTIONS OF THE PHLOEM PROTEINS OF CUCURBITAMAXIMA (PUMPKIN). European Journal of Biochemistry, 134, 561569.

Sauvion, N., Rahbe, Y., Peumans, W.J., Vandamme, E.J.M., Gatehouse, J.A. and Gatehouse, A.M.R. (1996) Effects of GNA and other mannose binding lectins on development and fecundity of the peach-potato aphid Myzus persicae. Entomologia Experimentalis Et Applicata, 79, 285293.

Schwarzkopf, A., Rosenberger, D., Niebergall, M., Gershenzon, J. and Kunert, G. (2013) To feed or not to feed: plant factors located in the epidermis, mesophyll, and sieve elements influence pea aphid's ability to feed on legume species. PLoS One, 8, e75298.

Spiller, N.J., Koenders, L. and Tjallingii, W.F. (1990) XYLEM INGESTION BY APHIDS - A STRATEGY FOR MAINTAINING WATER-BALANCE. Entomologia Experimentalis Et Applicata, 55, 101-104.

Thorpe, P., Escudero-Martinez, C., Cock, P., Laetsch, D., Eves-Van Den Akker, S. and Bos, J. (2018) Shared transcriptional control and disparate gain and loss of aphid parasitism genes and loci acquired via horizontal gene transfer. bioRxiv.

Tjallingii, W.F. (1978) ELECTRONIC RECORDING OF PENETRATION BEHAVIOR BY APHIDS. Entomologia Experimentalis Et Applicata, 24, 721-730.

Tjallingii, W.F. (1985a) ELECTRICAL NATURE OF RECORDED SIGNALS DURING STYLET PENETRATION BY APHIDS. Entomologia Experimentalis Et Applicata, 38, 177-186.

Tjallingii, W.F. (1985b) MEMBRANE-POTENTIALS AS AN INDICATION FOR PLANT-CELL PENETRATION BY APHID STYLETS. Entomologia Experimentalis Et Applicata, 38, 187-193.

Tjallingii, W.F. (1995) Aphid-plant interactions: What goes on in the depth of the tissues? Proceedings of the Section Experimental and Applied Entomology of the Netherlands Entomological Society (N.E.V.), Vol 6, 1995, 163-169.

Tjallingii, W.F. (2006) Salivary secretions by aphids interacting with proteins of phloem wound responses. Journal of Experimental Botany, 57, 739745. 
Tjallingii, W.F. and Esch, T.H. (1993) FINE-STRUCTURE OF APHID STYLET ROUTES IN PLANT-TISSUES IN CORRELATION WITH EPG SIGNALS. Physiological Entomology, 18, 317-328.

Turlings, T.C.J. and Ton, J. (2006) Exploiting scents of distress: the prospect of manipulating herbivore-induced plant odours to enhance the control of agricultural pests. Current Opinion in Plant Biology, 9, 421-427.

Verbeek, M., Piron, P.G.M., Dullemans, A.M., Cuperus, C. and Van Der Vlugt, R.A.A. (2010) Determination of aphid transmission efficiencies for $\mathrm{N}$, NTN and Wilga strains of Potato virus Y. Annals of Applied Biology, 156, 39-49.

Weisberg, S. and Fox, J. (2011) An R Companion to Applied Regression . Thousand Oaks: Sage.

Will, T. and Van Bel, A.J.E. (2006) Physical and chemical interactions between aphids and plants. Journal of Experimental Botany, 57, 729737.

Zadoks, J.C., Chang, T.T. and Konzak, C.F. (1974) DECIMAL CODE FOR GROWTH STAGES OF CEREALS. Weed Research, 14, 415-421.

Zhang, C.L., Shi, H.J., Chen, L., Wang, X.M., Lu, B.B., Zhang, S.P., Liang, Y.A., Liu, R.X., Qian, J., Sun, W.W., You, Z.Z. and Dong, H.S. (2011) Harpin-induced expression and transgenic overexpression of the phloem protein gene AtPP2-A1 in Arabidopsis repress phloem feeding of the green peach aphid Myzus persicae. Bmc Plant Biology, 11, 19. 